
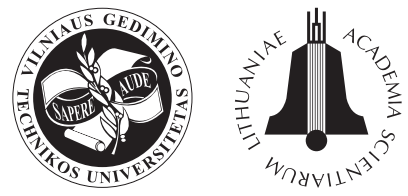

TRANSPORT

2010

25(4): 423-432

\title{
A NEW FUZZY ADDITIVE RATIO ASSESSMENT METHOD (ARAS-F). CASE STUDY: THE ANALYSIS OF FUZZY MULTIPLE CRITERIA IN ORDER TO SELECT THE LOGISTIC CENTERS LOCATION
}

\author{
Zenonas Turskis $^{1}$, Edmundas Kazimieras Zavadskas ${ }^{2}$ \\ 1, 2 Dept of Construction Technology and Management, Vilnius Gediminas Technical University, \\ Sauletekio al. 11, LT-10223 Vilnius, Lithuania \\ E-mails: ${ }^{1}$ zenonas.turskis@vgtu.lt; ${ }^{2}$ edmundas.zavadskas@vgtu.lt
}

Received 20 February 2010; accepted 15 November 2010

\begin{abstract}
The main approaches which are applied to select the logistic center are the methods of gravity center, analytic hierarchy process, similarity to ideal solution, fuzzy ranking, assessment, etc. Multiple Criteria Decision-Making (MCDM) combines analytical and inductive knowledge, describing a domain problem, which can be fuzzy and/or incomplete. The fuzzy MCDM (FMCDM) approach can explain the problem more appropriately. The purpose of the paper is to select the most suitable site for logistic centre among a set of alternatives, to help the stakeholders with the performance evaluation in an uncertain environment, where the subjectivity and vagueness of criteria are described by triangular fuzzy numbers. The paper presents a newly-developed ARAS-F method to solve different problems in transport, construction, economics, technology and sustainable development.
\end{abstract}

Keywords: fuzzy, multiple criteria decision making, ARAS method, ARAS-F method, operation research, logistic centres, location.

\section{Introduction}

Most decision problems that human beings face in the real world are gambles. Alternatives are the raw material of decision making. The aim of this article is simple: to enable the decision makers to construct successful realworld, fuzzy multiple criteria problem and solve them. There are three forms of applied thinking that all humans need in key situations: creative thinking, problem solving, and making the right choices based on several options. Humans need arguments for explaining choices which are already made, or for selecting among reasonable alternatives. Each alternative usually has pros and cons of various strengths, which are the measurements of rationality of the feasible.

According to (Rasmussen 1983), the solution process of decision making problem could be divided into three broad categories. At the lowest level is skill-based sensorimotor smooth behaviour. It represents a type of actions that requires very little or no conscious control to perform or execute an action once as intention is formed. At the second level is rule-based behaviour. It is characterised by the use of rules and procedures to select a course of action in a familiar work situation.

Knowledge-based behaviour represents the most advanced level of reasoning. A knowledge-based behav- iour is those tasks that are new, unfamiliar, unexpected or unique tasks. It represents a more advanced level of reasoning (Wirstad 1988).

Usually, decision-makers acts and make decisions in groups, but not autonomously.

In proper decision making it is necessary to evaluate the impacts of economic, technological, legislative, environmental, and social changes. According to the decision theorists the decision process follows a systematic, well structured procedure of action and uses well formulated rules, values and beliefs. To take the right decision is typically a very complicated process due to a number of factors:

- goal systems are highly complex combinations of single goals;

- relationships between them are unclear;

- it is difficult to find a relevant set of problem criteria, which should meet requirements of completeness, relevance, non-redundancy, meaningfulness, measurability, and value independence;

- a future development, which deals with large number of reasonable alternatives, is fuzzy;

- the decision-maker acts not as autonomous but in a group of stakeholders.

A number of approaches have been proposed for solving Multiple Criteria Decision-Making (MCDM) 
problems such as Analytical Hierarchy Process (AHP) (Morkvėnas et al. 2008; Maskeliūnaitè et al. 2009), Analytical Network Process (ANP) (Satty 1996), which deals with decisions without making assumptions about the independence of higher level elements from lower level elements and about the independence of the elements within a level, data envelopment analysis (DEA), Technique for Order Performance by similarity to Ideal Solution (TOPSIS) (Hwang and Yoon 1981), VIKOR, Complex Proportional Assessment (COPRAS), Simple Additive Weighting (SAW), etc. These are approaches which measure the alternative ratings and weights of the criteria and are crisp or expressed in precise numbers which depends upon decision maker's judgements or preferences (Wang and Lee 2009).

Authors of this paper applied and developed a lot of MCDM methods to solve the problems in transport, economics, management and construction (Zavadskas et al. 2008b; Turskis et al. 2009): MEW (Завадскас 1987; Zavadskas et al. 2009a), ordering feasible alternatives of making solutions in terms of preferability technique (Завадскас 1987; Turskis 2008), Additive Ratio Assessment Method (ARAS) (Zavadskas and Turskis 2010; Zavadskas et al. 2010c), SAW-G (Zavadskas et al. 2010b; Medineckiene et al. 2010), COPRAS-G (Zavadskas et al. 2008a, 2009b), a new logarithmic normalization method in the Game Theory (Zavadskas and Turskis 2008), Multi-Objective Optimization on the basis of the Ratio Analysis (MOORA) (Brauers and Zavadskas 2006; Brauers et al. 2008) etc.

\section{Fuzzy MCDM}

However, under many real cases crisp human judgements are vague and cannot be assessed with exact numeric values. Human's thinking and acting deals with the ill-structured decision problems in an uncertain environment. Human's decision making should take into account subjectivity. Fuzzy set theory allows decision makers to use incomplete or partially obtained information into the problem's solution model.

Fuzzy logic is an extension of the traditional logic to intermediate and approximate values that capture the meaning of words, human reasoning, and decision making. Fuzzy systems and logic has its origins in ancient Greek philosophy (Korner 1967). Zadeh (1965, 1971, $1975 a-c)$ made a crucial step in the design of a problem solving tool. He proposed and developed a concept of fuzzy logic in his seminal papers.

Bellman and Zadeh (1970) were the first who introduced fuzzy sets into the field of MCDM as an important tool to represent the uncertainty and imprecision in human decision making process involving multiple criteria.

'Fuzzy goals and fuzzy constraints can be defined precisely as fuzzy sets in the space of alternatives. A fuzzy decision, then, may be viewed as an intersection of the given goals and constraints. A maximizing decision is defined as a point in the space of alternatives at which the membership function of a fuzzy decision attains its maximum value.'
Fuzzy sets have a tremendous potential for multiple criteria problems solution in the fields of operation research, and its applications to various branches of sciences, engineering, economics and management. To resolve the ambiguity which frequently arises from human judgement, fuzzy set theory (Zadeh 1965) has been incorporated in many MCDM methods. The decision matrix is composed by fuzzy values. Fuzzy arithmetical operations should be used to produce the final aggregated scores for each alternative. The concept of fuzzy intervals (Yager and Filev 1994) is applied to simplify these computations and to permit operations with distinct kinds of membership functions.

FMCDM methods evaluate the alternative ratings and the weights of criteria on imprecision and vagueness expressed by fuzzy numbers i.e. fuzzy AHP, fuzzy ANP, fuzzy TOPSIS, fuzzy ELECTRE, fuzzy PROMETHEE, and fuzzy ORESTE. In fuzzy AHP and fuzzy ANP cases the preferences are required to be provided by decision makers. The earliest work in fuzzy AHP appeared in Van Laarhoven and Pedrycz (1983). Pan (2009) applied fuzzy Analytical Hierarchy Process (AHP) to evaluate alternatives of excavation construction related to multiple decision criteria.

Chen et al. (1992) first applied fuzzy numbers to establish fuzzy TOPSIS.

These methods can be used for strategic decision making. However, when the numbers of alternatives are more AHP, fuzzy AHP, ANP, and fuzzy ANP does not provide feasible solution.

These methods were modified and applied by various researchers to solve the selection problems in different fields.

\subsection{Basic Definitions}

In most cases, the classes of objects encountered in the real physical world do not have precisely defined criteria of membership. A fuzzy set is a class of objects with a continuum of membership grades. Such a set is characterized by a membership function which assigns to each object a grade of membership ranging between zero and one (Zadeh 1965). A fuzzy set $A$ defined in space $X$ is a set of pairs:

$$
A=\left\{\left(x, \mu_{A}(x)\right), x \in X\right\}, \forall x \in X,
$$

where: the fuzzy set $A$ is characterized by its membership function $\mu_{A}: X \rightarrow[0 ; 1]$ which associates with each element $x \in X$, a real number $\mu_{A}(x) \in[0 ; 1]$. The value $\mu_{A}(x)$ at $x$ represents the grade of membership of $x$ in $A$ and is interpreted as the membership degree to which $x$ belongs to $A$. So the closer the value $\mu_{A}(x)$ is to 1 , the more $x$ belongs to $A$.

A crisp or ordinary subset $A$ of $X$ can also be viewed as a fuzzy set in $X$ with membership function as its characteristic function, i.e.:

$$
\mu_{A}(x)=\left\{\begin{array}{l}
1, x \in A \\
0, x \notin A
\end{array}\right.
$$


The set $X$ is called a universe of discourse and can be written $\subseteq X$. Sometimes a fuzzy set $A$ in $X$ is denoted by list the ordered pairs $\left(x, \mu_{a}(x)\right)$, where the elements with zero degree are usually not listed. Thus a fuzzy set $A$ in $X$ can be represented as $A=\left\{\left(x, \mu_{A}(x)\right)\right\}$, where $x \in X$ and $\mu_{A}: X \rightarrow[0 ; 1]$.

When the universe of discourse is discrete and finite with cardinality $n$, that is $X=\left\{x_{1}, x_{1}, \ldots, x_{n}\right\}$, the fuzzy set $A$ can be represented as:

$$
\begin{aligned}
& A=\sum_{i=1}^{n} \frac{\mu_{A}\left(x_{i}\right)}{x_{i}}=\frac{\mu_{A}\left(x_{1}\right)}{x_{1}}+ \\
& \frac{\mu_{A}\left(x_{2}\right)}{x_{2}}+\cdots+\frac{\mu_{A}\left(x_{n}\right)}{x_{n}} .
\end{aligned}
$$

When the universe of discourse $X$ is an interval of real numbers, the fuzzy set $A$ can be expressed as:

$$
A=\int_{X} \frac{\mu_{A}(x)}{x} .
$$

A fuzzy number is defined to be a fuzzy triangular number $(\alpha, \beta, \gamma)$ if its membership function is fully described by three parameters $(\alpha<\beta<\gamma)$ :

$$
\mu_{A}(x)= \begin{cases}\frac{1}{\beta-\alpha} x-\frac{\alpha}{\beta-\alpha}, & \text { if } x \in[\alpha, \beta] ; \\ \frac{1}{\beta-\gamma} x-\frac{\alpha}{\beta-\gamma}, & \text { if } x \in[\beta, \gamma] \\ 0, & \text { otherwise. }\end{cases}
$$

\subsection{Defuzzification}

In order to obtain a crisp output, a defuzzification process is needed to be applied. Defuzzification is the process of producing a quantifiable result in fuzzy logic, given fuzzy sets and corresponding membership degrees. The output of the defuzzification process is a single number. Many defuzzification techniques have been proposed in the literature.

Various types of membership functions are used. The most commonly used membership functions are the following (Dubois and Prade 1988): triangular, trapezoid, linear, sigmoidal, $\pi$-type, and Gaussian.

The most typical fuzzy set membership function is triangular membership function (Fig. 1).

The basic operations of fuzzy triangular numbers $\tilde{n}_{1}$ and $\tilde{n}_{2}$ (Van Laarhoven and Pedrycz 1983) are defined as follows:

$\tilde{n}_{1} \oplus \tilde{n}_{2}=\left(n_{1 \alpha}+n_{2 \alpha}, n_{1 \beta}+n_{2 \beta}, n_{1 \gamma}+n_{2 \gamma}\right)$ addition;

$\tilde{n}_{1}(-) \tilde{n}_{2}=\left(n_{1 \alpha}-n_{2 \gamma}, n_{1 \beta}-n_{2 \beta}, n_{1 \gamma}-n_{2 \alpha}\right)$ substraction;

$\tilde{n}_{1} \otimes \tilde{n}_{2}=\left(n_{1 \alpha} \otimes n_{2 \alpha}, n_{1 \beta} \otimes n_{2 \beta}, n_{1 \gamma} \otimes n_{2 \gamma}\right)$ multiplication;(8)

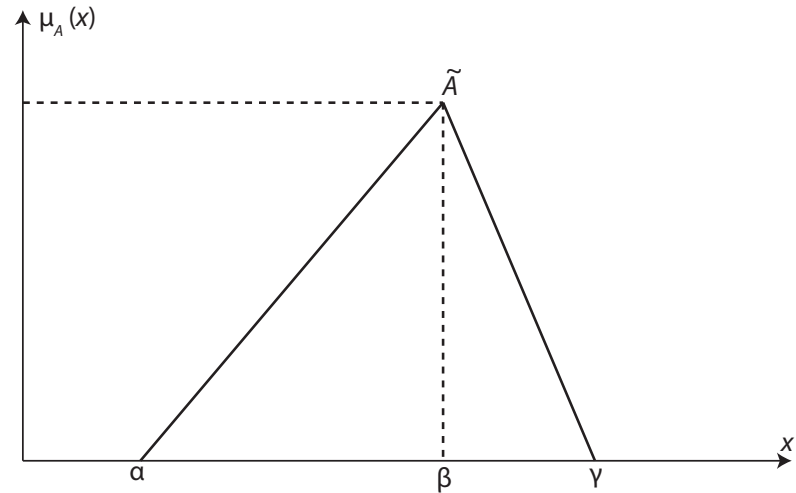

Fig. 1. Triangular membership function

$$
\begin{aligned}
& \tilde{n}_{1}(\div) \tilde{n}_{2}=\left(\frac{n_{1 \alpha}}{n_{2 \gamma}}, \frac{n_{1 \beta}}{n_{2 \beta}}, \frac{n_{1 \gamma}}{n_{2 \alpha}}\right) \text { division; } \\
& k \tilde{n}_{1}=\left(k n_{1 \alpha}, k n_{1 \beta}, k n_{1 \gamma}\right) \text { multiplication by constant; } \\
& \left(\tilde{n}_{1}\right)^{-1}=\left(\frac{1}{n_{1 \gamma}}, \frac{1}{n_{1 \beta}}, \frac{1}{n_{1 \alpha}}\right)
\end{aligned}
$$

\section{Criteria Weights Determination Applying Analytic Hierarchy Process (AHP)}

There are various approaches for assessing weights (Zavadskas et al. 2010a), e.g., the eigenvector method, SWARA (Keršulienè et al. 2010), expert method (Zavadskas and Vilutienè 2006), Entropy method, etc.

The decision is made by using the derived weights $w$ of the evaluative criteria (Saaty 1980). According to the Saaty, his experiments have shown that most individuals cannot compare more than seven objects (plus/ minus two). Based on this, Saaty established 9 objects as the upper limit of his integer scale for multiple pair wise comparisons (Table 1).

Table 1. The nine-point scale of pair wise comparison (according to Saaty (1980))

\begin{tabular}{lc}
\hline Definition & $\begin{array}{l}\text { Intensity of } \\
\text { importance }\end{array}$ \\
\hline Criteria $i$ and $j$ have equal importance & 1 \\
\hline $\begin{array}{l}\text { Criterion } i \text { is weakly more important } \\
\text { than criterion } j\end{array}$ & 5 \\
\hline $\begin{array}{l}\text { Criterion } i \text { is essentially (strongly) more } \\
\text { important than criterion } j\end{array}$ & 7 \\
\hline $\begin{array}{l}\text { Criterion } i \text { is very strongly } \\
\text { demonstrably) more important than } \\
\text { criterion } j\end{array}$ & 9 \\
\hline $\begin{array}{l}\text { Criterion } i \text { is absolutely more important } \\
\text { than criterion } j\end{array}$ & $2,4,6,8$ \\
\hline $\begin{array}{l}\text { Intermediate values between the two } \\
\text { adjacent judgements }\end{array}$ & Reciprocals \\
$\begin{array}{l}\text { If activity } i \text { has one of the nonzero } \\
\text { numbers assigned to it when compared } \\
\text { with activity } j \text { then, then } j \text { has reciprocal } \\
\text { value when compared with } i\end{array}$ & nonzero \\
\hline
\end{tabular}


In AHP the decision matrix is always a square matrix:

$$
A=\left(a_{i j}\right)=\left[\begin{array}{cccc}
1 & \frac{w_{1}}{w_{2}} & \cdots & \frac{w_{1}}{w_{m}} \\
\frac{w_{2}}{w_{1}} & 1 & \cdots & \frac{w_{2}}{w_{m}} \\
\vdots & \vdots & \ddots & \vdots \\
\frac{w_{m}}{w_{1}} & \frac{w_{m}}{w_{2}} & \cdots & 1
\end{array}\right],
$$

Fuzzy group weight is determined as follows:

After obtaining the criteria weights from AHP the synthesising of ratio judgements is done.

Suppose $\tilde{W}=\left[\overline{\tilde{w}_{1}, \tilde{w}_{n}}\right]=\left[\tilde{w}_{j}\right]$ is fuzzy group weight for $n$ criteria and $\tilde{w}_{j}$ is fuzzy triangular number:

$$
\tilde{w}_{j}=\left(w_{j l}, w_{j m}, w_{j u}\right)
$$

where: $w_{j l}=\min _{k} y_{j k}, j=\overline{1, n}, k=\overline{1, p}$ is minimum possible value; $w_{j \alpha}=\left(\prod_{k=1}^{p} y_{j k}\right)^{\frac{1}{p}}, j=\overline{1, n}, k=\overline{1, p}$ is the most possible value and $w_{j \beta}=\max _{k} y_{j k}, j=\overline{1, n}, k=\overline{1, p}$ is the maximal possible value of $j$-th criterion; $w_{j \gamma}=\max _{k} y_{j k}, j=\overline{1, n}, k=\overline{1, p}$.

\section{A New Fuzzy Additive Ratio Assessment (ARAS) method ARAS-F}

ARAS method (Zavadskas and Turskis 2010) is based on the argument that the phenomena of complicated world could be understood by using simple relative comparisons. It is argued that the ratio of the sum of normalized and weighted criteria scores, which describe alternative under consideration, to the sum of the values of normalized and weighted criteria, which describes the optimal alternative, is degree of optimality, which is reached by the alternative under comparison.

According to the ARAS method (Zavadskas and Turskis 2010; Tupenaitè et al. 2010), a utility function value determining the complex relative efficiency of a reasonable alternative is directly proportional to the relative effect of values and weights of the main criteria considered in a project.

The first stage is fuzzy decision-making matrix (FDMM) forming. In the FMCDM of the discrete optimization problem any problem which has to be solved is represented by the following DMM of preferences for $m$ reasonable alternatives (rows) rated on $n$ criteria (columns):

$$
\begin{gathered}
\tilde{X}=\left[\begin{array}{ccccc}
\tilde{x}_{01} & \cdots & \tilde{x}_{0 j} & \cdots & \tilde{x}_{0 n} \\
\vdots & \ddots & \vdots & \ddots & \vdots \\
\tilde{x}_{i 1} & \cdots & \tilde{x}_{i j} & \cdots & \tilde{x}_{i n} \\
\vdots & \ddots & \vdots & \ddots & \vdots \\
\tilde{x}_{m 1} & \cdots & \tilde{x}_{m j} & \cdots & \tilde{x}_{m n}
\end{array}\right], \\
i=\overline{0, m} ; j=\overline{1, n},
\end{gathered}
$$

where: $m$ - number of alternatives; $n$ - number of criteria describing each alternative; $\tilde{x}_{i j}$ - fuzzy value representing the performance value of the $i$ alternative in terms of the $j$ criterion; $\tilde{x}_{0 j}$ - optimal value of $j$ criterion. A tilde ' ' will be placed above a symbol if the symbol represents a fuzzy set.

If optimal value of $j$ criterion is unknown, then:

$\tilde{x}_{0 j}=\max _{i} \tilde{x}_{i j}$, if $\max _{i} \tilde{x}_{i j}$ is preferable, and

$\tilde{x}_{0 j}=\min _{i} \tilde{x}_{i j}^{*}$, if $\min _{i} \tilde{x}_{i j}^{*}$ is preferable.

Usually, the performance values $\tilde{x}_{i j}$ and the criteria weights $\tilde{w}_{j}$ are viewed as the entries of a DMM. The system of criteria as well as the values and initial weights of criteria are determined by experts. The information can be corrected by the interested parties, taking into account their goals and opportunities.

Then the determination of the priorities of alternatives is carried out in several stages.

Usually, the criteria have different dimensions. The purpose of the next stage is to receive dimensionless weighted values from the comparative criteria. In order to avoid the difficulties caused by different dimensions of the criteria, the ratio to the optimal value is used. There are various theories describing the ratio to the optimal value. However, the values are mapped either on the interval $[0 ; 1]$ or the interval $[0 ; \infty)$ by applying the normalization of a DMM.

In the second stage the initial values of all the criteria are normalized - defining values $\tilde{\bar{x}}_{i j}$ of normalised decision-making matrix $\bar{X}$ :

$$
\begin{gathered}
\tilde{\bar{X}}=\left[\begin{array}{ccccc}
\tilde{\bar{x}}_{01} & \ldots & \tilde{\bar{x}}_{0 j} & \ldots & \tilde{\bar{x}}_{0 n} \\
\vdots & \ddots & \vdots & \ddots & \vdots \\
\tilde{\bar{x}}_{i 1} & \ldots & \tilde{\bar{x}}_{i j} & \ldots & \tilde{\bar{x}}_{i n} \\
\vdots & \ddots & \vdots & \ddots & \vdots \\
\tilde{\bar{x}}_{m 1} & \ldots & \tilde{\bar{x}}_{m j} & \ldots & \tilde{\bar{x}}_{m n}
\end{array}\right], \\
i=\frac{0, m}{j} j=\overline{1, n} .
\end{gathered}
$$

The criteria, whose preferable values are maxima, are normalized as follows:

$$
\tilde{\bar{x}}_{i j}=\frac{\tilde{x}_{i j}}{\sum_{i=0}^{m} \tilde{x}_{i j}} \text {. }
$$

The criteria, whose preferable values are minima, are normalized by applying two-stage procedure:

$$
\tilde{x}_{i j}=\frac{1}{\tilde{x}_{i j}^{*}} ; \quad \tilde{\bar{x}}_{i j}=\frac{\tilde{x}_{i j}}{\sum_{i=0}^{m} \tilde{x}_{i j}} .
$$

When the dimensionless values of the criteria are known, all the criteria, originally having different dimensions, can be compared.

The third stage is defining normalized-weighted matrix $-\hat{X}$. It is possible to evaluate the criteria with 
weights $0<\tilde{w}_{j}<1$. Only well-founded weights should be used because weights are always subjective and influence the solution. The values of weight $w_{j}$ are usually determined by the expert evaluation method. The sum of weights $w_{j}$ would be limited as follows:

$$
\begin{aligned}
& \sum_{j=1}^{n} w_{j}=1 . \\
& \tilde{\hat{X}}=\left[\begin{array}{ccccc}
\tilde{\hat{x}}_{01} & \cdots & \tilde{\hat{x}}_{0 j} & \cdots & \tilde{\hat{x}}_{0 n} \\
\vdots & \ddots & \vdots & \ddots & \vdots \\
\tilde{\hat{x}}_{i 1} & \cdots & \tilde{\hat{x}}_{i j} & \cdots & \tilde{\hat{x}}_{i n} \\
\vdots & \ddots & \vdots & \ddots & \vdots \\
\tilde{\hat{x}}_{m 1} & \cdots & \tilde{\hat{x}}_{m j} & \cdots & \tilde{\hat{x}}_{m n}
\end{array}\right], \\
& i=\overline{0, m} ; j=\overline{1, n} .
\end{aligned}
$$

Normalized-weighted values of all the criteria are calculated as follows:

$$
\tilde{\hat{x}}_{i j}=\tilde{\bar{x}}_{i j} \tilde{w}_{j} ; \quad i=\overline{0, m},
$$

where: $w_{j}$ is the weight (importance) of the $j$ criterion; $\bar{x}_{i j}$ is the normalized rating of the $j$ criterion.

The following task is determining values of optimality function:

$$
\tilde{S}_{i}=\sum_{j=1}^{n} \tilde{\hat{x}}_{i j} ; \quad i=\overline{0, m},
$$

where $\tilde{S}_{i}$ is the value of optimality function of $i$-th alternative.

The biggest value is the best, and the least one is the worst. Taking into account the calculation process, the optimality function $\tilde{S}_{i}$ has a direct and proportional relationship with the values $\tilde{x}_{i j}$ and weights $\tilde{w}_{j}$ of the investigated criteria and their relative influence on the final result. Therefore, the greater the value of the optimality function $\tilde{S}_{i}$, the more effective the alternative. The priorities of alternatives can be determined according to the value $\tilde{S}_{i}$. Consequently, it is convenient to evaluate and rank decision alternatives when this method is used.

The result of fuzzy decision making for each alternative is fuzzy number $\tilde{S}_{i}$. There are several methods for defuzzification. The centre-of-area is the most practical and simple to apply to:

$$
S_{i}=\frac{1}{3}\left(S_{i \alpha}+S_{i \beta}+S_{i \gamma}\right) .
$$

The degree of the alternative utility is determined by a comparison of the variant, which is analysed, with the most ideal one $S_{0}$. The equation used for the calculation of the utility degree of an alternative $A_{i}$ is given below:

$$
K_{i}=\frac{S_{i}}{S_{0}} ; \quad i=\overline{0, m},
$$

where: $S_{i}$ and $S_{0}$ are the optimal criterion values, obtained from Eq. (23).
It is clear, that the calculated values $K_{i}$ are in the interval $[0 ; 1]$ and can be ordered in an increasing sequence, which is the wanted order of precedence. The complex relative efficiency of the reasonable alternative can be determined according to the utility function values.

\section{Case Study: The Analysis of Fuzzy Multiple Criteria in Order to Select the Logistic Centre Location}

The transport of freight, ranging from raw materials to finished goods, is essential to economic activity and to the quality of life in the EU. It makes the division of labour possible, allows economies of scale, and mobilises comparative advantages. Freight transport is therefore fundamental for European competitiveness (The EU's Freight Transport... 2007).

Basically an infrastructure project affects the transport system by the way transport of goods will lead to benefits within the logistic system of the company.

Trends towards globalization, integrated logistics and the development of Information and Communication Technologies are the factors reshaping the world's trading patterns and consequently physical trade flows (Vasilis Vasiliauskas and Jakubauskas 2007; Meidute 2007).

The development of an automatic traffic management helps to improve logistics (Jakimavičius and Burinskienè 2010).

There are five fundamental objectives of the government's transport policy:

- economy;

- environment;

- safety;

- accessibility;

- integration.

A modern society can effectively function only having an effective transport and logistics system. Road infrastructure is complex, and therefore the optimal choice of planned interventions is a delicate task often left to the road managers' subjective judgment (Šelih et al. 2008). The transportation system must work effectively to distribute those goods on customer's demand (Mačiulis et al. 2009; Vasilis Vasiliauskas and Barysienè 2008).

Strategic level logistical decisions typically have a long-lasting effect. This includes decisions regarding the number, location and capacities of manufacturing plants, and the flow of material through the logistics network (Bramel and Simchi-Levi 1999). The site selection of logistics centre is a key link to the chain of logisticscentre planning.

The financial evaluation of a new Logistics center is mainly performed and based on the viewpoint (and interests) of the private investor.

Logistics center is a space in a defined area which all activities relating to transport, logistics and the distribution of goods - both for national and international transit, are carried out by various operators on a commercial basis. Logistics centres make a significant contribution to the territorial and economic development of the area 
they are located. Regional logistics planning and development should be integrated with geography, economy, transportation, and other characteristics. Normally the logistics centres are located in a $100-150$ ha territory, however, sometimes the size can reach 500 ha. This creates a problem of security and comfort. At this point in time it is important to separate the terms of optimisation concerning the company and the society. The company is of course trying to arrange the supply chain in a way so it maximises its revenue. In this sense, the transport is a residual of the logistical planning while the minimisation of transport costs gives the same amount of attention as any other costs concerning the company. A welfare maximisation is, however, trying to optimize economic benefits towards the society. In this case an increase in transport can give a potential benefit to the society; however, it also provides a disadvantage by creating more pollution etc. In new EU countries the opposing side is often environmentally-friendly which on the basis of the environmental protection law can even stop the whole investment process (Jaržemskis 2007).

Economic assessment and transport modelling are essential for providing decision-makers with the evidence they need to reach soundly based decisions on transport policies and infrastructure schemes.

Case study describes newly developed solution methodology. The case study under consideration is limited in the optimality terms of logistic company.

The alternative sites are determined according to the planning logistics zone. Four location alternatives of logistics centre are under consideration: $A_{1}, A_{2}, A_{3}$ and $A_{4}$.

The main object is the relationship between the logistic principles and the investments which in this case are translated into four fundamental concepts or criteria (stakeholders' point of view):

- $C_{1}$ - investment cost $\left[10^{6} €\right]$, (optimal value is minimum);

$-C_{2}$ - operation time [years] (optimal value is maximum);

- $C_{3}$ - expansion possibility, [\%] (optimal value is maximum);

- $C_{4}$ - closeness to the demand market [kilometres], (optimal value is minimum).

The evaluation methodology, developed in this article is a specific tool, which can be integrated into a wider methodology for planning and evaluating investments in a new Logistics centre, when a mix of public and private funds exists.

In conventional mathematics data of problems are usually determined by the experts as crisp values in terms of classical mathematical reasoning. But in reality, in an imprecise and uncertain environment, it will be utmost unrealistic to assume that the knowledge and representation of an expert can come in a precise way (Senhupta and Pal 2009).

The analytic hierarchy process (AHP) was applied to calculate the crisp criteria weights by seven decision makers $\left(E_{1}, \ldots, E_{7}\right)$. The decision making process in this case depends on the risk attitude of the expert, which has a crucial role. Fig. 2 shows the relative weights based on four criteria in logistics centres location's performance.

The $\beta$ weights of each criterion (as it is depicted in Fig. 3) were $C_{1}$ - investment cost (0.137), $C_{2}$ - operation time (0.203), $C_{3}$ - expansion possibility (0.343), and $C_{4}-$ closeness to the demand market $(0.210)$.

The alternatives versus four criteria $C_{1}, C_{2}, C_{3}$ and $\mathrm{C}_{4}$ must be evaluated by seven stakeholders (decision makers) $E_{1}, E_{2}, \ldots, E_{7}$.

Decision makers' point of view about criteria and the performance of alternatives is given as a fuzzy decision making matrix $\tilde{X}$ (Table 2).

Tables $3-5$ shows the solution process according to the algorithm presented above. Table 6 presents the solution of the problem results and graphical representation of the obtained results.

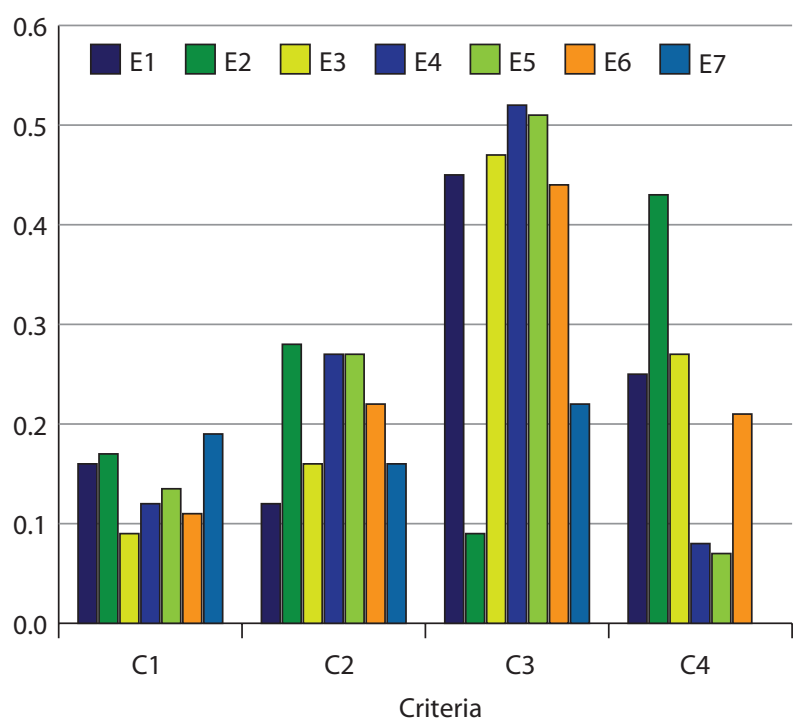

Fig. 2. Determined weights of criteria (seven stakeholders experts), which were obtained by applying AHP

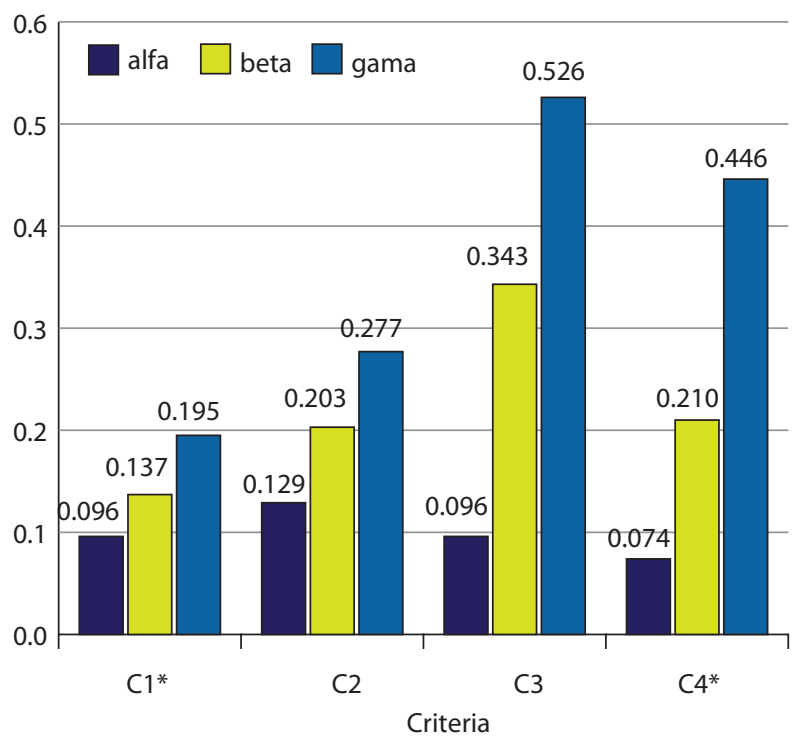

Fig. 3. Fuzzy weights of criteria 
Table 2. The rating of four criteria by decision makers

\begin{tabular}{|c|c|c|c|c|c|c|c|c|c|c|c|c|c|c|}
\hline \multirow{4}{*}{ Criterion } & \multirow{4}{*}{$\begin{array}{l}\text { Decision } \\
\text { maker }\end{array}$} & \multicolumn{12}{|c|}{ Alternatives } & \multirow{3}{*}{$\begin{array}{l}\text { Criterion weight } \\
\text { (AHP method) }\end{array}$} \\
\hline & & \multicolumn{3}{|c|}{$A_{1}$} & \multirow{2}{*}{\multicolumn{2}{|c|}{$A_{2}$}} & & \multicolumn{3}{|c|}{$A_{3}$} & \multirow{2}{*}{\multicolumn{3}{|c|}{$A_{4}$}} & \\
\hline & & & & & & & & & & & & & & \\
\hline & & & & & & & & & & & & & & \\
\hline \multirow{7}{*}{$C_{1}$} & $D_{1}$ & 16 & 17 & 18 & 10 & 11 & 13 & 18 & 22 & 19 & 17 & 20 & 22 & 0.156 \\
\hline & $D_{2}$ & 15 & 16 & 17 & 11 & 12 & 12 & 17 & 18 & 19 & 20 & 23 & 25 & 0.161 \\
\hline & $D_{3}$ & 17 & 17 & 18 & 9 & 10 & 13 & 19 & 20 & 21 & 17 & 20 & 22 & 0.096 \\
\hline & $D_{4}$ & 17 & 18 & 19 & 11 & 12 & 13 & 15 & 17 & 18 & 19 & 22 & 24 & 0.124 \\
\hline & $D_{5}$ & 15 & 16 & 18 & 9 & 11 & 13 & 16 & 19 & 21 & 19 & 22 & 24 & 0.138 \\
\hline & $D_{6}$ & 18 & 18 & 20 & 9 & 11 & 14 & 15 & 17 & 19 & 17 & 20 & 22 & 0.111 \\
\hline & $D_{7}$ & 15 & 17 & 20 & 9 & 10 & 11 & 15 & 18 & 20 & 18 & 21 & 23 & 0.195 \\
\hline \multirow{7}{*}{$C_{2}$} & $D_{1}$ & 25 & 27 & 35 & 20 & 25 & 35 & 25 & 33 & 40 & 20 & 28 & 30 & 0.129 \\
\hline & $\mathrm{D}_{2}$ & 25 & 27 & 33 & 15 & 28 & 40 & 30 & 33 & 40 & 30 & 33 & 35 & 0.277 \\
\hline & $D_{3}$ & 20 & 22 & 33 & 25 & 33 & 40 & 25 & 28 & 40 & 25 & 33 & 35 & 0.161 \\
\hline & $D_{4}$ & 25 & 27 & 33 & 20 & 30 & 45 & 30 & 33 & 40 & 30 & 33 & 38 & 0.273 \\
\hline & $D_{5}$ & 20 & 27 & 33 & 25 & 30 & 45 & 30 & 33 & 45 & 30 & 38 & 40 & 0.275 \\
\hline & $D_{6}$ & 20 & 22 & 30 & 15 & 25 & 40 & 30 & 38 & 45 & 25 & 28 & 33 & 0.222 \\
\hline & $D_{7}$ & 25 & 32 & 35 & 20 & 30 & 35 & 25 & 28 & 35 & 30 & 33 & 35 & 0.149 \\
\hline \multirow{7}{*}{$C_{3}$} & $D_{1}$ & 15 & 20 & 35 & 20 & 25 & 35 & 27 & 30 & 33 & 15 & 22 & 35 & 0.448 \\
\hline & $D_{2}$ & 20 & 25 & 35 & 22 & 25 & 30 & 27 & 30 & 33 & 20 & 22 & 30 & 0.096 \\
\hline & $D_{3}$ & 15 & 25 & 30 & 15 & 20 & 25 & 25 & 30 & 33 & 17 & 27 & 35 & 0.466 \\
\hline & $D_{4}$ & 25 & 30 & 35 & 25 & 30 & 35 & 22 & 25 & 33 & 20 & 27 & 30 & 0.526 \\
\hline & $D_{5}$ & 15 & 20 & 30 & 20 & 25 & 30 & 20 & 30 & 33 & 30 & 32 & 35 & 0.512 \\
\hline & $D_{6}$ & 25 & 30 & 35 & 25 & 28 & 30 & 30 & 35 & 33 & 25 & 27 & 40 & 0.444 \\
\hline & $D_{7}$ & 15 & 25 & 30 & 15 & 22 & 25 & 22 & 25 & 30 & 30 & 32 & 40 & 0.231 \\
\hline \multirow{7}{*}{$C_{4}$} & $D_{1}$ & 14 & 16 & 18 & 8 & 9.5 & 13 & 8.5 & 10 & 12.5 & 7.5 & 9.5 & 12.5 & 0.269 \\
\hline & $D_{2}$ & 12 & 14 & 15 & 7 & 10 & 12 & 6 & 8 & 9 & 5 & 7 & 9 & 0.446 \\
\hline & $D_{3}$ & 11 & 13 & 15 & 7 & 9.5 & 15 & 7 & 8.5 & 10 & 5 & 7.5 & 13 & 0.277 \\
\hline & $D_{4}$ & 12 & 14 & 17 & 7 & 9 & 11 & 6 & 8.5 & 10 & 6 & 7.5 & 11 & 0.077 \\
\hline & $D_{5}$ & 11 & 14 & 16 & 9.5 & 11.5 & 14.5 & 8 & 9 & 10 & 6 & 8 & 9 & 0.074 \\
\hline & $D_{6}$ & 11 & 14 & 19 & 8 & 10 & 11 & 9 & 10.5 & 12 & 8 & 10.5 & 13 & 0.222 \\
\hline & $D_{7}$ & 14 & 16 & 19 & 10 & 12.5 & 15 & 8 & 9 & 11 & 5 & 8 & 10 & 0.425 \\
\hline
\end{tabular}

Table 3. The fuzzy decision matrix and fuzzy weights of four alternatives

\begin{tabular}{|c|c|c|c|c|c|c|c|c|c|c|c|c|c|c|c|}
\hline \multirow{4}{*}{ Criterion } & \multicolumn{12}{|c|}{ Alternatives } & \multirow{2}{*}{\multicolumn{3}{|c|}{$\begin{array}{c}\text { Fuzzy group } \\
\text { weight }\end{array}$}} \\
\hline & \multicolumn{3}{|c|}{$A_{1}$} & \multicolumn{2}{|r|}{$A_{2}$} & & \multicolumn{3}{|c|}{$A_{3}$} & \multicolumn{3}{|c|}{$A_{4}$} & & & \\
\hline & \multicolumn{12}{|c|}{ Ratings } & \multicolumn{3}{|c|}{$\tilde{w}_{j}$} \\
\hline & & & & & & & & & & & & & $w_{j \alpha}$ & $w_{j \beta}$ & $w_{j \gamma}$ \\
\hline$C_{1}^{*}$ & 15.0 & 17.0 & 20.0 & 9.0 & 11.0 & 14.0 & 15.0 & 18.6 & 21.0 & 17.0 & 21.1 & 25.0 & 0.096 & 0.137 & 0.195 \\
\hline$C_{2}$ & 20.0 & 26.1 & 35.0 & 15.0 & 28.6 & 45.0 & 25.0 & 32.1 & 45.0 & 20.0 & 32.1 & 40.0 & 0.129 & 0.203 & 0.277 \\
\hline$C_{3}$ & 15.0 & 24.7 & 35.0 & 15.0 & 24.8 & 35.0 & 20.0 & 29.1 & 33.0 & 15.0 & 26.7 & 40.0 & 0.096 & 0.343 & 0.526 \\
\hline$C_{4}^{*}$ & 11.0 & 14.4 & 19.0 & 7.0 & 10.2 & 15.0 & 6.0 & 9.0 & 12.5 & 5.0 & 8.2 & 13.0 & 0.074 & 0.210 & 0.446 \\
\hline Remark: & optim & am va & ue of & riteric & on is $r$ & inim & & & & & & & & & \\
\hline
\end{tabular}

Table 4. The changed fuzzy decision making matrix

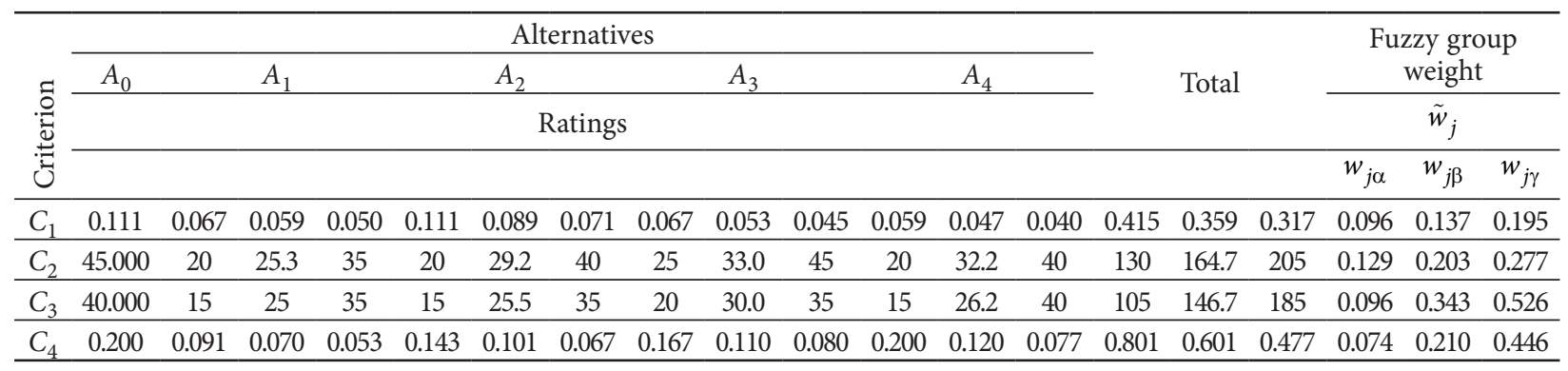


Table 5. The normalised fuzzy decision making matrix

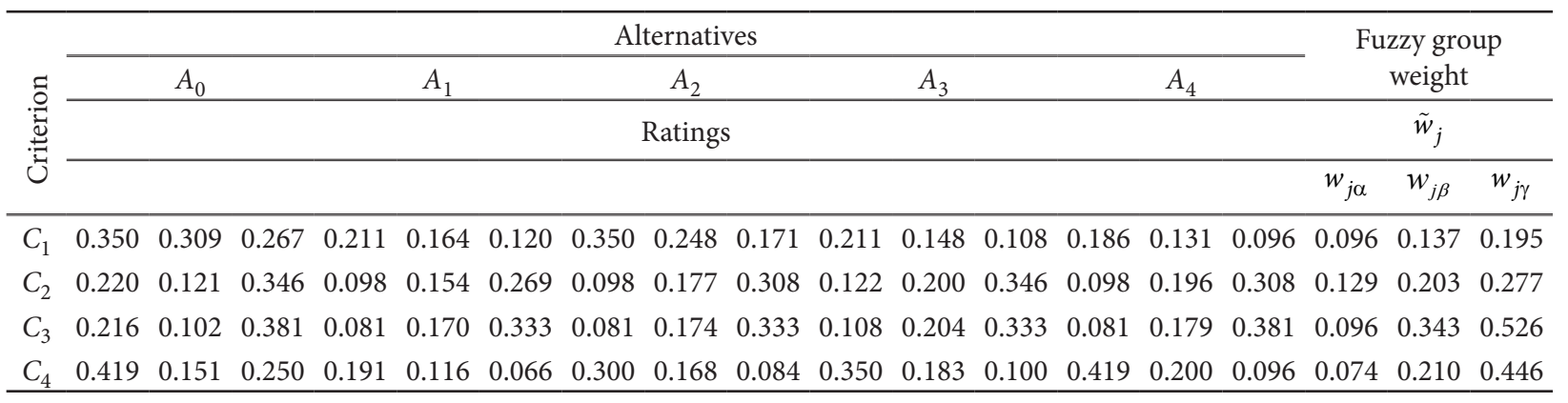

Table 6. The normalised-weighted fuzzy decision making matrix and solution results

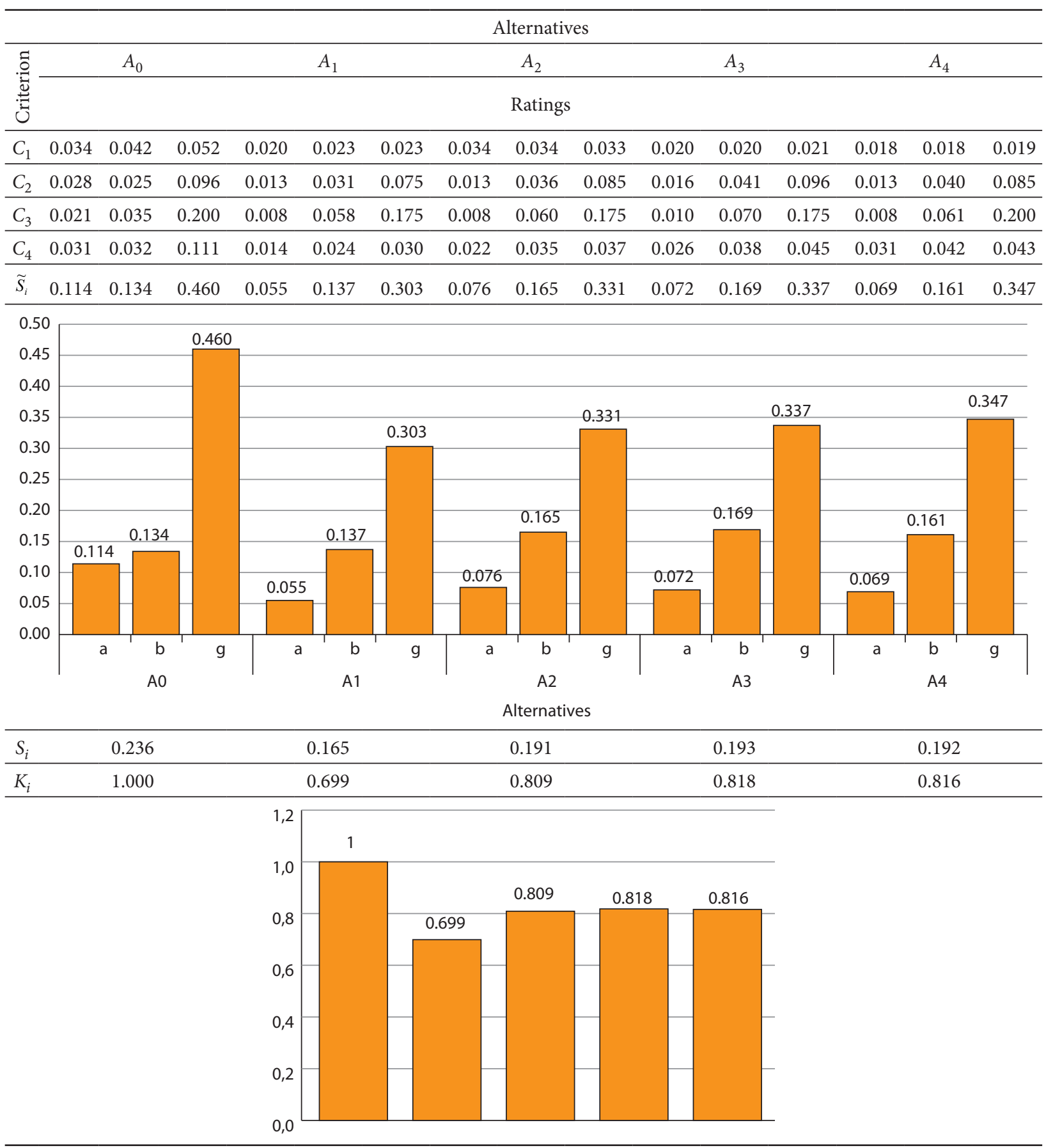




\section{Conclusions}

The traditional approaches of optimization, statistical and econometric analysis used within the engineering context are often based on the assumption that the considered problem is well formulated and decision-makers usually consider the existence of a single objective, evaluation criterion or point of view that underlies the conducted analysis. In such a case the solution of engineering problems is easy to obtain.

However, the modelling of engineering problems is based on a different kind of logic, taking into consideration the existence of multiple criteria, the conflicting aims of decision maker, the complex, subjective and different nature of the evaluation process, and the participation of several decision makers.

Overall, the main advantages that the MCDM provides in decision making, could be summarized in the following aspects: the possibility to analyze complex problems; the possibility to aggregate both quantitative and qualitative criteria in the evaluation process; the possibility of good evidence of decisions; the possibility for decision-maker to participate actively in the decision-making process and the application of flexible scientific methods in the decision making process.

The applications which may be generated from or adapted to fuzzy logic are wide-ranging.

According to the newly proposed ARAS-F method, the utility function value determining the complex efficiency of a feasible alternative is directly proportional to the relative effect of values and weights of the main criteria considered in a project.

The degree of the alternative utility is determined by a comparison of the variant, which is analysed, with the ideally best one.

It can be stated that the ratio with an optimal alternative may be used in cases when it is seeking to rank alternatives and find ways of improving alternative projects.

In conclusion, ARAS-F method has a promising future in the construction engineering field, because he offers a highly methodological basis for fuzzy decision support.

With an illustrative example: selection of logistics' centre location the proposed methodology is validated. It is found that there are four main criteria which must be considered: investment cost ( $\beta$ weight equals to 0.137 ), operation time ( $\beta$ weight equals to 0.203 ), expansion possibility ( $\beta$ weight equals to 0.343 ), and closeness to the demand market ( $\beta$ weight equals to $0.210)$.

Weights results show that stakeholders are more concern about the expansion possibility and the closeness to the demand market than the operation time and investment costs.

In this paper it is supposed to deal with fuzzy data to help the model to be very applicable due to lack of certainty and crisp data in real word situations especially about qualitative variables.

\section{References}

Bellman, R. E.; Zadeh, L. A. 1970. Decision-making in a fuzzy environment, Management Science 17(4): B-141-B-164. doi:10.1287/mnsc.17.4.B141

Bramel, J.; Simchi-Levi, D. 1999. The Logic of Logistics. Theory, Algorithms, and Applications for Logistics Management. Springer, Corrected edition. $281 \mathrm{p}$.

Brauers, W. K. M.; Zavadskas, E. K. 2006. The MOORA method and its application to privatization in a transition economy, Control and Cybernetics 35(2): 445-469.

Brauers, W. K. M.; Zavadskas, E. K.; Peldschus, F.; Turskis, Z. 2008. Multi-objective decision-making for road design, Transport 23(3): 183-193.

doi:10.3846/1648-4142.2008.23.183-193

Chen, S.-J.; Hwang, C. L.; Hwang, F. P. 1992. Fuzzy Multiple Attribute Decision Making: Methods and Applications. Springer. $536 \mathrm{p}$.

Dubois, D.; Prade, H. 1988. Possibility Theory. 1st edition. Springer. $280 \mathrm{p}$.

Hwang, C.-L.; Yoon, K. 1981. Multiple Attribute Decision Making: Methods and Applications; A State-of-the-Art Survey. 1 st edition. Springer. 259 p.

Jakimavičius, M.; Burinskiené, M. 2010. Route planning methodology of an advanced traveller information system in Vilnius city, Transport 25(2): 171-177. doi:10.3846/transport.2010.21

Jaržemskis, A. 2007. Research on public logistics centre as tool for cooperation, Transport 22(1): 50-54.

Keršuliene, V.; Zavadskas, E. K.; Turskis, Z. 2010. Selection of rational dispute resolution method by applying new stepwise weight assessment ratio analysis (SWARA), Journal of Business Economics and Management 11(2): 243-258. doi:10.3846/jbem.2010.12

Korner, S. 1967. Laws of thought, in The Encyclopedia of Philosophy, edited by Edwards, P. Vol. 4: 414-417.

Mačiulis, A.; Vasilis Vasiliauskas, A.; Jakubauskas, G. 2009. The impact of transport on the competitiveness of national economy, Transport 24(2): 93-99. doi:10.3846/1648-4142.2009.24.93-99

Maskeliūnaitė, L.; Sivilevičius, H.; Podvezko, V. 2009. Research on the quality of passenger transportation by railway, Transport 24(2): 100-112. doi:10.3846/1648-4142.2009.24.100-112

Medineckiene, M.; Turskis, Z.; Zavadskas, E. K. 2010. Sustainable construction taking into account the building impact on the environment, Journal of Environmental Engineering and Landscape Management 18(2): 118-127. doi:10.3846/jeelm.2010.14

Meidute, I. 2007. Economical evaluation of logistics centres establishment, Transport 22(2): 111-117.

Morkvėnas, R.; Bivainis, J.; Jaržemskis, A. 2008. Assessment of employee's knowledge potential in transport sector, Transport 23(3): 258-265. doi:10.3846/1648-4142.2008.23.258-265

Pan, N. F. 2009. Selecting an appropriate excavation construction method based on qualitative assessments, Expert Systems with Applications 36(3), Part 1: 5481-5490. doi:10.1016/j.eswa.2008.06.097

Rasmussen, J. 1983. Skills, rules, and knowledge - signals, signs, and symbols, and other distinctions in human-performance models, IEEE Transactions on Systems, Man, and Cybernetics 13(3): 257-266. 
Saaty, T. L. 1980. The Analytic Hierarchy Process: Planning, Priority Setting, Resource Allocation. Mcgraw-Hill. 287 p.

Saaty, T. L. 1996. The Analytic Network Process. RWS Publications, Pittsburgh.

Sengupta, A.; Pal, T. K. 2009. Fuzzy Preference Ordering of Interval Numbers in Decision Problems. 1st edition. Springer. $166 \mathrm{p}$.

Šelih, J.; Kne, A.; Srdić, A.; Žura, M. 2008. Multiple-criteria decision support system in highway infrastructure management, Transport 23(4): 299-305. doi:10.3846/1648-4142.2008.23.299-305

The EU'S Freight Transport Agenda: Boosting the Efficiency, Integration and Sustainability of Freight Transport in Europe. 2007. Commission of the European Communities. Available from Internet: <http://ec.europa.eu/transport/logistics/ freight_logistics_action_plan/doc/action_plan/2007_com_ freight_agenda_en.pdf $>$.

Tupènaite, L.; Zavadskas, E. K.; Kaklauskas, A.; Turskis, Z.; Seniut, M. 2010. Multiple criteria assessment of alternatives for built and human environment renovation, Journal of Civil Engineering and Management 16(2): 257-266. doi:10.3846/jcem.2010.30

Turskis, Z. 2008. Multi-attribute contractors ranking method by applying ordering of feasible alternatives of solutions in terms of preferability technique, Technological and Economic Development of Economy 14(2): 224-239. doi:10.3846/1392-8619.2008.14.224-239

Turskis, Z.; Zavadskas, E. K.; Peldschus, F. 2009. Multi-criteria optimization system for decision making in construction design and management, Inzinerine Ekonomika - Engineering Economics (1): 7-17.

Van Laarhoven, P. J. M.; Pedrycz, W. 1983. A fuzzy extension of Saaty's priority theory, Fuzzy Sets and Systems 11(1-3): 199-227. doi:10.1016/S0165-0114(83)80082-7

Vasilis Vasiliauskas, A.; Barysienė, J. 2008. Analysis of Lithuanian transport sector possibilities in the context of European-Asian trade relations, Transport 23(1): 21-25. doi:10.3846/1648-4142.2008.23.21-25

Vasilis Vasiliauskas, A.; Jakubauskas, G. 2007. Principle and benefits of third party logistics approach when managing logistics supply chain, Transport 22(2): 68-72.

Wang, T.-C.; Lee, H.-D. 2009. Developing a fuzzy TOPSIS approach based on subjective weights and objective weights, Expert Systems with Applications 36(5): 8980-8985. doi:10.1016/j.eswa.2008.11.035

Wirstad, J. 1988. On knowledge structures for process operators, in Tasks, Errors, and Mental Models, edited by Goodstein, L. P.; Andersen, H. B.; Olsen, S. E., 50-69.

Yager, R. R.; Filev, D. P. 1994. Essentials of Fuzzy Modeling and Control. 1st edition. Wiley. 408 p.

Zadeh, L. A. 1965. Fuzzy sets, Information and Control 8(3): 338-353. doi:10.1016/S0019-9958(65)90241-X

Zadeh, L. A. 1971. Similarity relations and fuzzy orderings, Information Sciences 3(2): 177-200. doi:10.1016/S0020-0255(71)80005-1

Zadeh, L. A. 1975a. The concept of a linguistic variable and its application to approximate reasoning - I, Information Sciences 8(3): 199-249. doi:10.1016/0020-0255(75)90036-5

Zadeh, L. A. 1975b. The concept of a linguistic variable and its application to approximate reasoning - II, Information Sciences 8(4): 301-357. doi:10.1016/0020-0255(75)90046-8

Zadeh, L. A. 1975c. The concept of a linguistic variable and its application to approximate reasoning - III, Information Sciences 9(1): 43-80. doi:10.1016/0020-0255(75)90017-1
Zavadskas, E. K.; Kaklauskas, A.; Turskis, Z.; Kalibatas, D. 2009a. An approach to multi-attribute assessment of indoor environment before and after refurbishment of dwellings, Journal of Environmental Engineering and Landscape Management 17(1): 5-11. doi:10.3846/1648-6897.2009.17.5-11

Zavadskas, E. K.; Kaklauskas, A.; Turskis, Z.; Tamošaitienè, J. 2009b. Multi-attribute decision-making model by applying grey numbers, Informatica 20(2): 305-320.

Zavadskas, E. K.; Kaklauskas, A.; Turskis, Z.; Tamošaitienè, J. 2008a. Selection of the effective dwelling house walls applying attributes determined in intervals, Journal of Civil Engineering and Management 14(2): 85-93. doi:10.3846/1392-3730.2008.14.3

Zavadskas, E. K.; Liias, R.;Turskis, Z. 2008b. Multi-attribute decision-making methods for assessment of quality in bridges and road construction: state-of-the-art survey, The Baltic Journal of Road and Bridge Engineering 3(3): 152160. doi:10.3846/1822-427X.2008.3.152-160

Zavadskas, E. K.; Turskis, Z. 2008. A new logarithmic normalization method in the game theory, Informatica 19(2): 303-314.

Zavadskas, E. K.; Turskis, Z. 2010. A new additive ratio assessment (ARAS) method in multi-criteria decision making, Technological and Economic Development of Economy 16(2): 159-172. doi:10.3846/tede.2010.10

Zavadskas, E. K.; Turskis, Z.; Ustinovichius, L.; Shevchenko, G. 2010a. Attributes weights determining peculiarities in multiple attribute decision making methods, Inzinerine Ekonomika - Engineering Economics 21(1): 32-43.

Zavadskas, E. K.; Vilutienė, T.; Turskis, Z.; Tamošaitienė, J. 2010b. Contractor selection for construction works by applying SAW-G and TOPSIS grey techniques, Journal of Business Economics and Management 11(1): 34-55. doi: 10.3846/jbem. 2010.03

Zavadskas, E. K.; Turskis, Z.; Vilutienè, T. 2010c. Multiple criteria analysis of foundation instalment alternatives by applying additive ratio assessment (ARAS) method, Archives of Civil and Mechanical Engineering 10(3): 123-141.

Zavadskas, E. K.; Vilutienè, T. 2006. A multiple criteria evaluation of multi-family apartment block's maintenance contractors: I - Model for maintenance contractor evaluation and the determination of its selection criteria, Building and Environment 41(5): 621-632. doi:10.1016/j.buildenv.2005.02.019

Завадскас, Э.-К. 1987. Комплексная оценка и выбор ресурсосберегающих решений в строительстве [Zavadskas, E. K. Complex evaluation and choosing of constructions' resource saving solutions in construction]. Вильнюс: Мокслас. 212 с. (in Russian). 